\title{
EVALUATION OF THE USE OF ULTRASONIC ACTIVATED POLY-D-L-LACTIC ACID PINS AND MESHES FOR HORIZONTAL SOFT TISSUE AUGMENTATION AROUND DENTAL IMPLANTS
}

\author{
Eman A.S. El-Mahalawy ${ }^{1} D S$, Ahmad M. Hommos² PhD, Gehan S. Kotry ${ }^{3} P h D$
} \begin{abstract}
INTRODUCTION: Horizontal ridge defects are a common consequence of tooth loss. They present an esthetic problem, especially if the edentulous site is in the maxillary esthetic zone and indicated for implant placement.

A novel system using ultrasonic waves to activate pins and meshes made of completely resorbable poly-D-L-lactic acid has been recently introduced. It is commonly used in the augmentation of alveolar ridge defects, but has not been tried for guided soft tissue augmentation.

OBJECTIVES: clinical evaluation of the efficacy of ultrasonic activated poly-D-L-lactic acid pins and meshes for guided soft tissue augmentation of horizontal defects present around dental implants.

MATERIALS AND METHODS: study comprised of eight patients having localized horizontal soft tissue defects around dental implants. 'Guided soft tissue augmentation' technique was applied to manage these defects using ultrasonic activated poly-D-L-lactic acid pins and meshes. Patients recorded visual analogue scores for the first two weeks post-operatively. The augmented defects were evaluated for soft tissue thickness and pink esthetic score at one and three months post-operatively.

RESULTS: there was a statistically significant increase in soft tissue thickness and fill in all treated defects together with an improvement of the pink esthetic score when compared to the baseline values. Patients had a mean visual analogue score of $(0.0 \pm 0.0)$ as of the fifth postoperative day.

CONCLUSIONS: augmentation of horizontal soft tissue defects using ultrasonic activated poly-D-L-lactic acid pins and meshes is a less invasive and effective clinical procedure to increase soft tissue thickness around dental implants together with the reconstruction of gingival
\end{abstract} contours to match those of adjacent natural teeth.

KEYWORDS: dental implants, esthetics, horizontal ridge defects, SonicWeld ${ }$, soft tissue

1-Instructor at Oral Medicine, Periodontology, Oral Diagnosis and Radiology Department, Faculty of Dentistry, Alexandria University, Alexandria, Egypt. 2- Professor of Oral Medicine, Periodontology, Oral Diagnosis and Radiology Department, Faculty of Dentistry, Alexandria University, Alexandria, Egypt. 3-Assistant professor of Oral Medicine, Periodontology, Oral Diagnosis and Radiology Department, Faculty of Dentistry, Alexandria University, Alexandria, Egypt.

\section{INTRODUCTION}

Tooth loss is followed by a series of inevitable biologic processes that result in bone resorption. The pattern of bone resorption can be horizontal, vertical or a combination of both (1). The horizontal pattern is the second most common pattern of post-extraction ridge defects (2). Soft tissue contours usually follow the architecture of underlying bone resulting in additional deficiency of soft tissue (1). When the edentulous ridge is localized, it appears as a concave area between the root prominences of adjacent teeth (3).

Resorption of residual alveolar ridges may result in the placement of dental implants in sites with less than ideal hard and/or soft tissue volumes (4). With the shift of focus on the importance of esthetics as a determinant factor for implant success, it became of outmost importance to manage these defects (5).

Management of horizontal ridge defects around implants can be done using hard or soft tissue augmentation procedures. Decision making depends on the size of defect and amount of residual bone around the implant $(6,7)$. An implant should be surrounded by at least $1.8-2 \mathrm{~mm}$ of bone thickness in order to consider managing the surrounding defect with soft tissue augmentation procedures (8).

Clinicians managed horizontal soft tissue defects either using the same techniques for pontic site development or modified them to accommodate the different nature of periimplant tissues (9).

Autogenous grafts have been widely used for soft tissue augmentation purposes, for pontic site development or around implants $(10,11)$. Subepithelial connective tissue graft (SCTG) was especially used for the volumetric increase of soft tissues and is considered the gold standard for the management of such defects (12). However, several limitations were encountered with SCTG such as the need for a second donor surgical site, anatomical limitations, inadequate quantity of graft material and post-operative pain and numbness (13).

Therefore, alternative materials were proposed such as grafts from allogenic or xenogenic origins and tissue engineering based materials (14-16).

Salama et al (17) in 1995 introduced a new process for soft tissue augmentation around implants in the esthetic zone and called it 'guided soft tissue augmentation'. Their technique depended on tenting a mucoperiosteal flap using submerged healing abutments creating a dead space that will fill with a blood clot. Later, this blood clot reorganized into soft tissue. The same technique was later used by Marx et al (18) for the augmentation of large vertical bone defects. Its concept depended on the tenting of mucoperiosteal flaps using screws to expand the soft tissue and therefore eliminate the pressure exerted on the underlying graft material.

Recently, a novel poly-D-L-lactic acid (PDLLA) system ,with components that are activated using ultrasonic waves , was introduced. Once activated, the pins melt and flow in between bone trabeculae. They are then welded to PDLLA meshes. This process creates a three-dimensional firmly anchored tenting system. Furthermore, PDLLA can completely disintegrate into water and carbon dioxide leaving no by-products after 8-12 weeks (19). 
This system has never been tested for soft tissue augmentation around dental implants. Its effects on these tissues remain unknown.

\section{MATERIALS AND METHODS}

\section{A) Materials:}

\section{Study Subjects:}

Study included eight patients, 5 females and 3 males, with ages ranging between 20 to 40 years, having horizontal soft tissue defects around dental implants in the maxillary anterior esthetic zone. All patients had well osseointegrated implants with healthy surrounding tissues showing no signs of peri-implantitis. The surgical procedure was performed during the second stage surgery. All patients were required to maintain a modified O'Leary index of $\leq 10 \%$ (20). Smokers, alcoholics, pregnant or lactating females and medically compromised patients were all excluded from the study.

1) Ultrasonic activated PDLLA pins (SonicX ${ }^{\circledR}$ pins, KLS Martin, Mühlheim, Germany). Biodegradable pins made of $100 \%$ PDLLA, $5 \mathrm{~mm}$ in length and $2.1 \mathrm{~mm}$ in diameter, supplied in sterile packages containing 5 pins each. They were used to tent mucoperiosteal flaps.

2) Ultrasonic activated PDLLA meshes (ResorbX $\AA$ meshes, KLS Martin, Mühlheim, Germany). Biodegradable perforated membranes with dimensions of $25 \mathrm{~mm}$ in width, $25 \mathrm{~mm}$ in length and $0.1 \mathrm{~mm}$ in thickness, also made of $100 \%$ PDLLA and supplied in sterile packages. They were used to support the tented mucoperiosteal flaps.

\section{B) Methods}

1) Pre-surgical phase

- The nature and objectives of the study were carefully explained to each participant and all subjects gave their informed consent of the study. The study was approved by the institutional ethical committee on clinical trials involving humans (Faculty of Dentistry, Alexandria University) (IRB NO: 00010556 - IORG: 0008839) and conducted in accordance with the guidelines of the World Medical Association Declaration of Helsinki (ethical principles for medical research involving human subjects) (21).

- Phase I therapy was performed for each patient.

- Acrylic stents were constructed to standardize the three sites of measurement (mesial, distal and mid-surface of the defect) at baseline, one and 3 months respectively.

- One day before the surgery, patients were instructed to take $1 \mathrm{gm}$ amoxicillin clavulanate (Augmentin, GlaxoSmithKline, Cairo, A.R.E) one hour before the procedure and instructed to continue this medication every 12 hours for 5 days post-operatively.

- Just before the surgery, patients were instructed to rinse for 30 seconds with $0.12 \%$ chlorhexidne gluconate mouthwash (Hexitol, Arab Drug Company (ADCO), Cairo, A.R.E).

\section{2) Surgical phase}

- The surgical site was disinfected using providone iodine (Betadine, Nile Pharma, Cairo, A.R.E).

- Local buccal and palatal infiltration anesthesia was given to all patients (articaine hypochloride $4 \%$ and levonordefrin) (Septocaine ${ }^{\circledR}$, Septodont, Saint-Maurdes-Fossés, France) (Figure 1-2).

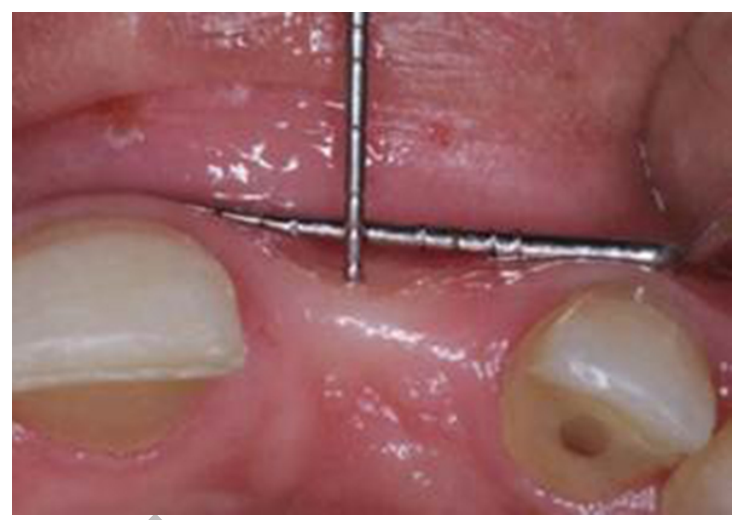

Figure 1: Photograph showing the size of the horizontal ridge defect pre-operatively.

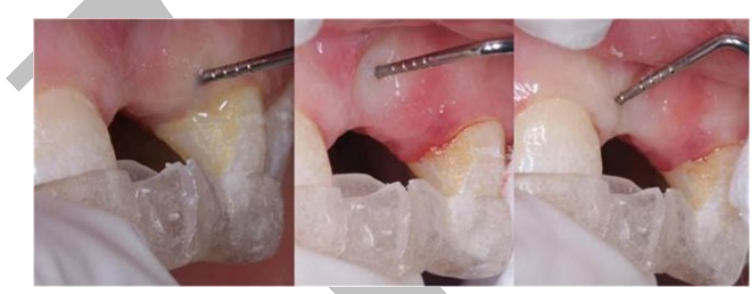

Figure 2: Photograph showing pre-operative measurement of STT through transgingival probing at 3 different points.

- Paracrestal incisions were done using Bard Parker blade number 15 (KLS Martin, Mühlheim, Germany).

- Fully reflected mucoperiosteal flaps were elevated using periosteal elevators.

- Pilot holes were drilled in the bone mesial and distal to the defect, at least $3 \mathrm{~mm}$ in depth using $2.1 \mathrm{~mm}$ diameter drills.

- $\quad$ PDLLA pins were inserted into the pilot holes leaving the rest of the length of the pins and their heads required for tenting above the bone level by mounting them on sonotrodes that send ultrasonic vibrations that liquefy the pins and integrate them with the bone (Figure 3).

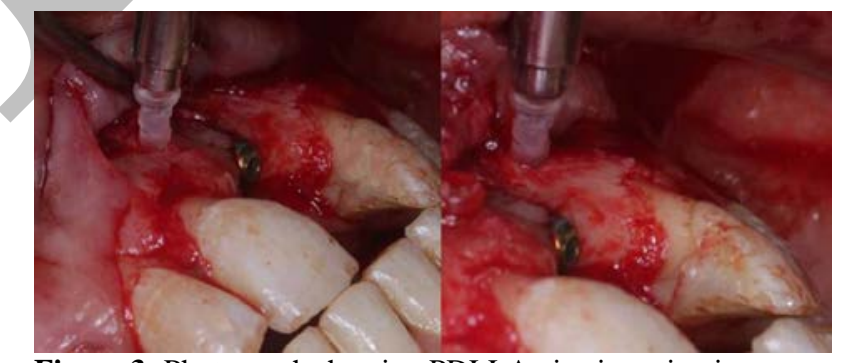

Figure 3: Photograph showing PDLLA pins insertion in predrilled pilot holes by activation with ultrasonic waves.

- $\quad$ PDLLA mesh was cut to the desired shape (according to the size of the defect).

- PDLLA mesh was placed over the pins and both were welded together using the SonicWeld ${ }^{\circledR}$ unit (Figure 4).

- Any rough edges were smoothened using scissors.

- Periosteal releasing incisions were done to ensure tension free flaps.

- Flaps were sutured using $4 / 0$ non-resorbable sutures (Ethicon, New Jersey, USA). 


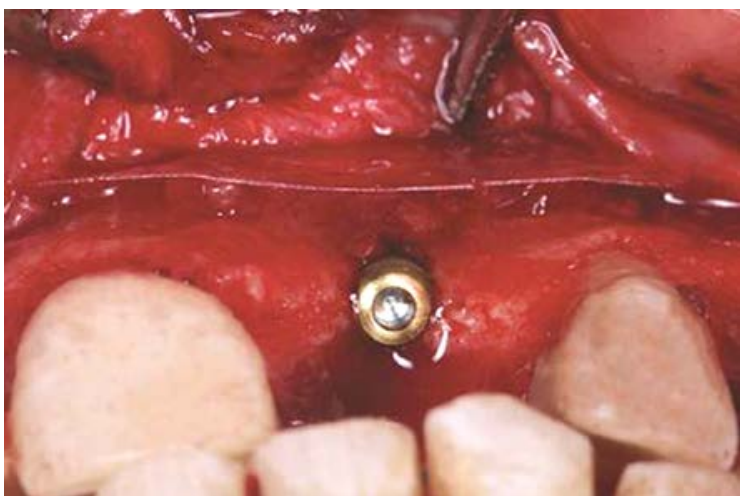

Figure 4: Photograph showing PDLLA pins in place with the corresponding welded mesh.

\section{3) Post-surgical phase}

- Postoperative instructions were given to the patients including oral hygiene instructions and $0.12 \%$ chlorhexidine gluconate mouthwash (Hexitol, Arab Drug Company (ADCO), Cairo, A.R.E.) 3 times daily as of the second day of the surgery and maintained for 2 weeks.

- Non-steroidal anti-inflammatory drugs were prescribed; ibuprofen 400 mg (Brufen, Abbott, Cairo, A.R.E); 1 tablet 3 times daily after meals for 4 days.

- Patients were seen 7 days after the surgery and sutures were removed after 14 days.

\section{4) Clinical evaluation}

- Subjective pain assessment was performed by all patients using visual analogue score (VAS). Pain severity was recorded by each patient starting on the day of the surgery and continued every 2 days until day 15 (22).

- Transgingival probing was made to measure soft tissue thickness (STT) at baseline then again at 1 and 3 months post-operatively (Figure 5 and Figure 6). After local anesthesia administration, a periodontal probe was used to pierce the soft tissue at 3 different points (at the midsurface of the defect and $2 \mathrm{~mm}$ mesially and distally). Those points were pre-determined through acrylic stents fabricated pre-operatively for standardization purposes throughout the study period. When the periodontal probe reached cortical bone, the measured length was recorded and rounded to the nearest half $\mathrm{mm}$ (23)

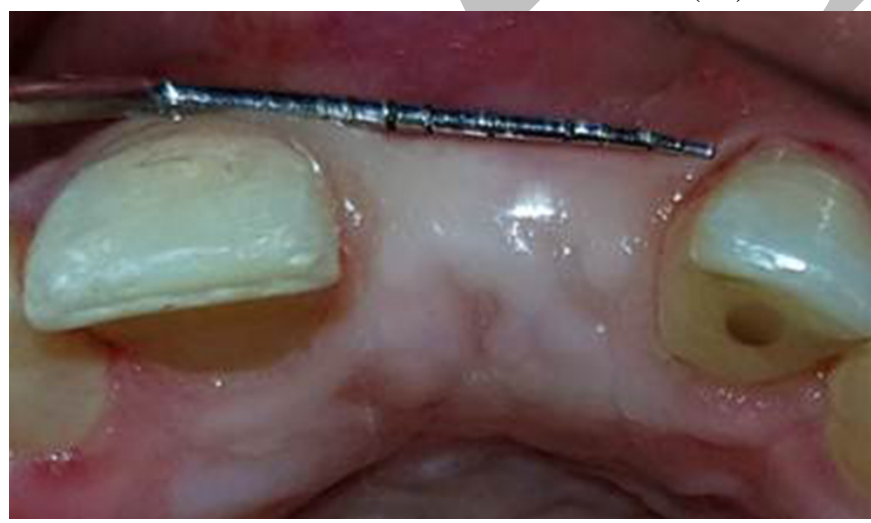

Figure 5: Photograph showing volumetric soft tissue augmentation of the horizontal ridge defect post-operatively

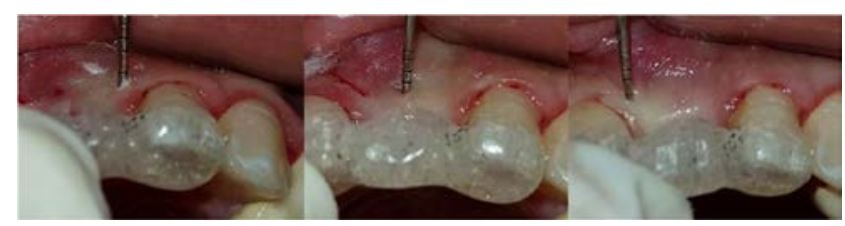

Figure 6: Photograph showing post-operative measurement of STT through transgingival probing at 3 different points.

- Peri-implant soft tissue changes were recorded using the pink esthetic score (PES) at baseline and after 3 months. In brief, seven variables were evaluated: mesial papilla, distal papilla, soft tissue level, soft tissue contour, alveolar process deficiencies, soft tissue color and texture. A '0-1-2 scoring system' was used, 0 being the lowest and 2 being the highest value. Then value of all the variables are added together to obtain a total score, with a maximum achievable score of 14 (24).

\section{Statistical analysis}

Data were fed to the computer and analyzed using IBM SPSS software package version 20.0. (Armonk, NY: IBM Corp) (25) Qualitative data were described using number and percent. The Kolmogorov-Smirnov test was used to verify the normality of distribution. Quantitative data were described using range (minimum and maximum), mean, standard deviation and median. Significance of the obtained results was judged at the $5 \%$ level.

Differences in average and mid-surface STT differences were compared at different times of the study using Friedman test. Differences in PES values were compared between baseline and 3 months using paired t-test.

\section{RESULTS}

\section{Clinical Observations}

All patients tolerated the surgical procedures well. Following the operation, healing was uneventful and no adverse reactions such as postoperative infection or allergies were recorded in the treated sites.

\section{Clinical Results}

VAS had a mean value of $(2.38 \pm 2.20)$ at first day postoperatively. This mean value decreased significantly to $(0.50 \pm 0.53)$ at third day, then decreased to $(0.13 \pm 0.35)$ at fifth day. Patients reported no pain after the fifth postoperative day $(\mathrm{VAS}=0.0)$.

Data collected through transgingival probing was compared at different times of the study period, as an average value of the 3 sites of measurement (Table 1). Mean STT values at the mid-surface of the defect were also compared at different times of the study (Table 2).

With regards to the average STT values, there was a statistically significant increase in mean STT values at 1 and 3 months $(4.62 \pm 0.55) \mathrm{mm}$ when compared to baseline values of $(3.21 \pm 0.89) \mathrm{mm}\left(\mathrm{p}=0.003^{*}\right)$. However, comparing mean STT values at 1 month and at 3 months, no statistically significant difference was found $(\mathrm{p}=1.000)$. A mean percentage of change of $(51.15 \pm 33.29) \%$ was obtained at 1 and maintained until 3 months postoperatively.

As when comparing mean STT values at the mid-surface of the defect, there was a statistically significant increase at 1 and 3 months (6.25 \pm 0.89$) \mathrm{mm}$ when compared to baseline values of $(3.25 \pm 0.71) \mathrm{mm}\left(\mathrm{p}=0.003^{*}\right)$. However, comparing mean STT values at 1 month and at 3 months, no statistically significant difference was found $(p=1.000)$. 
A mean percentage of change of $(96.87 \pm 30.52) \%$ was obtained at 1 month and maintained until 3 months postoperatively.

With respect to the PES, a statistically significant increase was noted when comparing mean values of baseline $(10.13 \pm 1.25)$ and 3 months $(12.38 \pm 1.30)$ $(\mathrm{p}<0.001 *)$, with a mean percentage of change of (22.5 \pm 5.17$) \%$ (Table 3).

Table (1): Descriptive analysis of the studied cases according to STT (Average).

\begin{tabular}{|c|c|c|c|c|c||}
\hline $\begin{array}{c}\text { Soft Tissue } \\
\text { Thickness (mms) } \\
\text { (average) }\end{array}$ & Baseline & One month & $\begin{array}{c}\text { Three } \\
\text { months }\end{array}$ & ${ }^{\mathrm{Fr}} \boldsymbol{\chi}^{2}$ & $\mathbf{p}$ \\
\hline Min. - Max. & $2.0-4.67$ & $4.0-5.67$ & $4.0-5.67$ & & \\
Mean \pm SD. & $3.21 \pm 0.89$ & $4.62 \pm 0.55$ & $4.62 \pm 0.55$ & $16.0^{*}$ & $\begin{array}{c}<0.001 \\
* \\
\text { Median }\end{array}$ \\
\hline $\begin{array}{c}\text { Sig. bet. periods } \\
\text { \% change from } \\
\text { baseline }\end{array}$ & \multicolumn{2}{|c|}{$\mathrm{p}_{1}=0.003^{*}, \mathrm{p}_{2}=0.003^{*}, \mathrm{p}_{3}=1.000$} & \\
\hline
\end{tabular}

Table (2): Descriptive analysis of the studied cases according to STT (Mid-surface).

\begin{tabular}{|c|c|c|c|c|c||}
\hline $\begin{array}{c}\text { Soft Tissue } \\
\text { Thickness (mms) } \\
\text { (Mid-surface) }\end{array}$ & Baseline & One month & $\begin{array}{c}\text { Three } \\
\text { months }\end{array}$ & ${ }^{F r} \chi^{2}$ & p \\
\hline Min. - Max. & $2.0-4.0$ & $5.0-7.0$ & $5.0-7.0$ & & \\
Mean \pm SD. & $3.25 \pm 0.71$ & $6.25 \pm 0.89$ & $6.25 \pm 0.89$ & $16.0^{*}$ \\
Median & 3.0 & 6.50 & 6.50 & $<0.001$ \\
\hline Sig. bet. periods & $\mathrm{p}_{1}=0.003^{*}, \mathrm{p}_{2}=0.003^{*}, \mathrm{p}_{3}=1.000$ & & \\
\hline $\begin{array}{c}\text { \% change from } \\
\text { baseline }\end{array}$ & \multicolumn{3}{|c|}{$96.87 \pm 30.52$} & $\begin{array}{c}96.87 \pm 30.5 \\
2\end{array}$ & \\
\hline
\end{tabular}

Table (3): Descriptive analysis of the studied cases according to PES.

\begin{tabular}{|c|c|c|c|c||}
\hline Pink Esthetic Score & Baseline & $\begin{array}{c}\text { Three } \\
\text { months }\end{array}$ & t & p \\
\hline Min. - Max. & $9.0-12.0$ & $11.0-14.0$ & & \\
Mean \pm SD. & $10.13 \pm 1.25$ & $12.38 \pm 1.30$ & $\underset{*}{13.748}$ & $\underset{*}{<.001}$ \\
Median & 10.0 & 12.50 & & \\
\hline \% change & \multicolumn{2}{|c|}{$22.5 \pm 5.17$} & & \\
\hline
\end{tabular}

\section{DISCUSSION}

The management of horizontal ridge defects represents one of the clinical challenges faced in every day practice. When these defects are present in a site where dental implants are placed, the clinical condition becomes more complicated because of the high esthetic expectations of patients. Consequently, these defects must be augmented using hard or soft tissue augmentation procedures with the ultimate goal of reconstruction of normal gingival architecture that mimics that of adjacent natural teeth $(3,26)$.

There is almost a generalized agreement about the lack of sufficient clinical data discussing the development of optimum peri-implant hard and soft tissues. Despite that, autogenous soft tissue grafts are the most commonly used materials for soft tissue augmentation (12).

There is also no general consensus about the ideal soft tissue volume needed around dental implants for functional stability (27). However, this soft tissue volume is deemed of paramount importance for esthetic purposes and sometimes can even be used to compensate hard tissue discrepancies. In a two-dimensional buccolingual manner, soft tissue volume should be no less than $2 \mathrm{~mm}(28,29)$. However, it has not been evaluated in a three-dimensional manner as a single parameter and in long term studies.

The 'screw tent pole' technique was introduced in the literature early in the 21st century and was used with success for the purpose of guided bone regeneration of horizontal or vertical ridge defects $(30,31)$.

To the best of our knowledge, this is the first attempt to use this technique for soft tissue augmentation, rather than bone, using ultrasonic activated PDLLA pins and meshes. This clinical study evaluated the potential of this technique in the reconstruction of horizontal soft tissue defects and increasing soft tissue thickness around dental implants.

The present study revealed a significant increase of STT values (average of three points of measurement and at midsurface alone) at three months when compared to baseline. Also there was a significant increase in STT values at one month when compared to baseline. However, there was no significant difference between 1 and 3 months. This may be attributed to the support provided by the PDLLA mesh when welded to the heads of PDLLA pins. The mesh causes expansion of soft tissue to eliminate any pressure exerted by the tissues on the defect. This may have allowed the undisturbed reorganization of the formed blood clot that filled the intentionally created dead space without any interference.

These findings are in agreement with another study conducted by Wiesner et al (32) in 2010 that aimed at augmenting soft tissue thickness around dental implants placed in the posterior part of the mandible using SCTG. Both studies succeeded in increasing STT at the mid-surface of the defect. However, when comparing the values of STT, SCTG gave a mean increase of $(1.20 \pm 0.63) \mathrm{mm}$ after one year of loading, whereas the current study resulted in an increase of about $3 \mathrm{~mm}$ at the end of the 3 months follow up period. Although the difference is significantly in favor of our study, the results may not be comparable because of different periods of data collection and the documented shrinkage of SCTG over time.

The results of the current study are in contrast with a study by Migliorati et al (33) in 2015, where a SCTG of 1 to $2 \mathrm{~mm}$ thickness was used to augment STT around implants in anterior maxilla. Mean STT at baseline was $(1.1 \pm 0.7) \mathrm{mm}$. It increased to $(3.5 \pm 0.7) \mathrm{mm}$ immediately after augmentation procedure then decreased to (2.3 \pm 0.8$)$, $(1.8 \pm 0.8) \mathrm{mm}$ at three and twelve months post-operatively respectively. From these results it can be concluded that the STT increase obtained through SCTG is at its peak immediately after the surgical application and continues to decrease over time. This means that even at the peak of its effect, SCTG still results in less STT increase than that obtained through the technique employed in the current study.

A systematic review by Poskevicius et al (34) in 2017 studying soft tissue changes after soft tissue grafting 
procedures concluded that the maximum shrinkage of the SCTG occurs in the first 3 months post-operatively. This is unlike the present study, where augmented soft tissue thickness was maintained throughout the entire 3 months follow up period. This may be attributed to the fact that components used for space maintenance start their disintegration process after 8 to 12 weeks and can last up to two years, providing the necessary time for the blood clot to reorganize into soft tissue. On the other hand, SCTG starts and continues to shrink during the entire first year after its application.

The increase in STT described in the present study may also be the cause of improvement of peri-implant soft tissue biotype. Although there is a lack of consensus about the classification of peri-implant soft tissue biotype, however thicker tissues have more blood supply and are less susceptible to recession and exposure of the underlying metallic color (35).

The results of this study are found to be consistent with the conclusions drawn from the previous clinical studies of Chen et al (36), Kan et al (37) and Nisapakultron et al (38) where they emphasized the importance of the presence of thick peri-implant tissues for a better soft tissue marginal stability and overall prognosis. To the best of our knowledge, there are no opposite opinions to the importance of the presence of thick peri-implant tissue biotype and its effect on the success and longevity of implants.

As for the PES, there was a significant increase from $(10.13 \pm 1.25)$ at baseline to $(12.38 \pm 1.30)$ at 3 months postoperatively. This finding reflects better esthetic outcomes and it might be explained by the fact that out of the seven variables that comprise the PES, only the value of the soft tissue contour was affected by the 'guided soft tissue augmentation' procedure performed in this study. This reflects a possible correlation between STT and PES. This conclusion is in agreement with results drawn from studies conducted by Wiesner et al (32) and Migliorati et al (33), where a significant increase in PES values to $(11.32 \pm 1.63)$ and (7.15 \pm 1.75$)$ respectively resulted after augmentation of STT with SCTG. Those values although reflecting an improvement of peri-implant soft tissue esthetics, are still lower than those in the current study.

A remarkable finding in this study is that the VAS values reached $(0.0 \pm 0.0)$ after a maximum of 5 postoperative days. This finding is in complete disagreement with conclusions drawn by other clinicians who used SCTG and reported severe post-operative pain. This is considered one of the most serious limitations of SCTG that drove researchers to find alternative techniques. The postoperative pain is expected due to the presence of two separate surgical sites, including recipient site and donor site in the palate and the longer chair time of the procedure. This was reported by Zucchelli et al (39) in their study conducted in 2010 to compare between de-epithelialized free gingival graft and SCTG for root coverage. In that study, patients were asked to record VAS during the first post-operative week. Mean VAS values were $(3.1 \pm 1.99)$ for the group managed with de-epithelialized free gingival graft and $(2.65 \pm 2.18)$ for the group managed with SCTG. The values of both groups were significantly higher than the values recorded in the current study, making 'guided soft tissue augmentation' a superior technique to autogenous grafts harvested from the palate in terms of patient morbidity.

\section{CONCLUSION}

From the results of the current study it can be concluded that horizontal soft tissue augmentation using ultrasonic activated PDLLA pins and meshes is a safe and easy method for peri-implant soft tissue management.

\section{CONFLICT OF INTEREST}

The authors declare that they have no conflicts of interest.

\section{REFERENCES}

1. Tan WL, Wong TLT, Wong MCM, Lang NP. A systematic review of post-extractional alveolar hard and soft tissue dimensional changes in humans. Clin Oral Implants Res. 2012;23:1-21.

2. Abrams H, Kopczyk RA, Kaplan AL. Incidence of anterior ridge deformities in partially edentulous patients. J Prosthet Dent. 1987;57:191-4.

3. Ioannou AL, Kotsakis GA, McHale MG, Lareau DE, Hinrichs JE, Romanos GE. Soft Tissue Surgical Procedures for Optimizing Anterior Implant Esthetics. Int J Dent. 2015;2015:740764.

4. Farmer M, Darby I. Ridge dimensional changes following single-tooth extraction in the aesthetic zone. Clin Oral Implants Res. 2014;25:272-7.

5. Bartee BK. Extraction site reconstruction for alveolar ridge preservation. Part 1: rationale and materials selection. J Oral Implantol. 2001;27:187-93.

6. Cairo F, Pagliaro U, Nieri M. Soft tissue management at implant sites. J Clin Periodontol. 2008;35:163-7.

7. Zuhr O, Bäumer D, Hürzeler M. The addition of soft tissue replacement grafts in plastic periodontal and implant surgery: Critical elements in design and execution. J Clin Periodontol. 2014;41:S123-42.

8. Spray JR, Black CG, Morris HF, Ochi S. The Influence of Bone Thickness on Facial Marginal Bone Response: Stage 1 Placement Through Stage 2 Uncovering. Ann Periodontol. 2000;5:119-28.

9. Park SH, Wang HL. Pouch roll technique for implant soft tissue augmentation: a variation of the modified roll technique. Int $\mathrm{J}$ Periodontics Restorative Dent. 2012;32:e116-21.

10.Zucchelli G, Mounssif I. Periodontal plastic surgery. Periodontol 2000. 2015;68:333-68.

11. Esposito M, Maghaireh H, Mg G, Ziounas I, Hv W. Interventions for replacing missing teeth: management of soft tissues for dental implants (Review). Cochrane Database Syst Rev. 2012;15: CD006697.

12. Thoma DS, Benić GI, Zwahlen M, Hämmerle CHF, Jung RE. A systematic review assessing soft tissue augmentation techniques. Clin Oral Implants Res. 2009;20:146-65.

13. Del Pizzo M, Modica F, Bethaz N, Priotto P, Romagnoli R. The connective tissue graft: a comparative clinical evaluation of wound healing at the palatal donor site. $\mathrm{J}$ Clin Periodontol. 2002;29:848-54.

14. Park JB. Increasing the width of keratinized mucosa around endosseous implant using acellular dermal matrix allograft. Implant Dent. 2006;15:275-81.

15. Nocini PF, Castellani R, Zanotti G, Gelpi F, Covani U, Marconcini S, et al. Extensive keratinized tissue augmentation during implant rehabilitation after Le Fort I osteotomy: Using a new porcine collagen membrane 
(Mucoderm). J Craniofac Surg. 2014;25:799-803.

16.Glaum R, Wiedmann-Al-Ahmad M, Huebner U, Schmelzeisen R. Tissue engineering of composite grafts: Cocultivation of human oral keratinocytes and human osteoblast-like cells on laminin-coated polycarbonate membranes and equine collagen membranes under different culture conditions. J Biomed Mater Res A. 2010;93:704-15.

17. Salama H, Salama M, Garber D, Adar P. Developing optimal peri-implant papillae within the esthetic zone: guided soft tissue augmentation. J Esthet Dent. 1995;7:125.

18. Marx RE, Shellenberger T, Wimsatt J, Correa P. Severely resorbed mandible: Predictable reconstruction with soft tissue matrix expansion (tent pole) grafts. J Oral Maxillofac Surg. 2002;60:878-88.

19. Heidemann W, Jeschkeit S, Ruffieux K, Fischer JH, Wagner M, Krüger G, et al. Degradation of poly (D, L) lactide implants with or without addition of calciumphosphates in vivo. Biomaterials. 2001;22:2371-81.

20. O'Leary TJ, Drake RB, Naylor JE. The plaque control record. J Periodontol. 1972;43:38.

21. Bădărău DO. Declaration of Helsinki. In: Mental Health Practitioner’s Guide to HIV/AIDS. Finland: Springer; 2013. 181-3.

22. Hawker GA, Mian S, Kendzerska T, French M. Measures of adult pain: Visual Analog Scale for Pain (VAS Pain), Numeric Rating Scale for Pain (NRS Pain), McGill Pain Questionnaire (MPQ), Short-Form McGill Pain Questionnaire (SF-MPQ), Chronic Pain Grade Scale (CPGS), Short Form-36 Bodily Pain Scale (SF-36 BPS), and Measure of Intermittent and Constant Osteoarthritis Pain (ICOAP). Arthritis Care Res (Hoboken). 2011;63:S240-52.

23. Vandana KL, Savitha B. Thickness of gingiva in association with age, gender and dental arch location. J Clin Periodontol. 2005;32:828-30.

24. Fürhauser R, Florescu D, Benesch T, Haas R, Mailath G, Watzek G. Evaluation of soft tissue around single-tooth implant crowns: the pink esthetic score. Clin Oral Implants Res. 2005;16:639-44.

25. Kirkpatrick LA, Feeney BC. A simple guide to IBM SPSS: for version 20.0. Belmont, CA: Wadsworth Cengage Learning; 2012.

26. Belser UC, Schmid B, Higginbottom F, Buser D. Outcome analysis of implant restorations located in the anterior maxilla: a review of the recent literature. Int $\mathrm{J}$ Oral Maxillofac Implants. 2004;19:30-42.

27. Schneider D, Grunder U, Ender A, Hämmerle CHF, Jung RE. Volume gain and stability of peri-implant tissue following bone and soft tissue augmentation: 1-year results from a prospective cohort study. Clin Oral Implants Res. 2011;22:28-37.

28. Benic GI, Mokti M, Chen CJ, Weber HP, Hämmerle CH, Gallucci GO. Dimensions of buccal bone and mucosa at immediately placed implants after 7 years: A clinical and cone beam computed tomography study. Clin Oral Implants Res. 2012;23:560-6.

29. Jung RE, Holderegger C, Sailer I, Khraisat A, Suter A, Hämmerle $\mathrm{CH}$. The effect of all-ceramic and porcelainfused-to-metal restorations on marginal peri-implant soft tissue color: a randomized controlled clinical trial. Int J Periodontics Restorative Dent. 2008;28: 357-65.

30. Caldwell G, Mills M, Finlayson R, Mealey B. Lateral Alveolar Ridge Augmentation Using Tenting Screws, Acellular Dermal Matrix, and Freeze-Dried Bone
Allograft Alone or with Particulate Autogenous Bone. Int J Periodontics Restor Dent. 2015;35:75-83.

31. Beitlitum I, Artzi Z, Nemcovsky CE. Clinical evaluation of particulate allogeneic with and without autogenous bone grafts and resorbable collagen membranes for bone augmentation of atrophic alveolar ridges. Clin Oral Implants Res. 2010;21:1242-50.

32. Wiesner G, Esposito M, Worthington $\mathrm{H}$, Schlee $\mathrm{M}$. Connective tissue grafts for thickening peri-implant tissues at implant placement. One-year results from an explanatory split-mouth randomised controlled clinical trial. Eur J Oral Implantol. 2010;3:27-35.

33. Migliorati M, Amorfini L, Signori A, Biavati AS, Benedicenti S. Clinical and Aesthetic Outcome with Post-Extractive Implants with or without Soft Tissue Augmentation: A 2-Year Randomized Clinical Trial. Clin Implant Dent Relat Res. 2015;17:983-95.

34. Poskevicius L, Sidlauskas A, Galindo-Moreno P, Juodzbalys G. Dimensional soft tissue changes following soft tissue grafting in conjunction with implant placement or around present dental implants: a systematic review. Clin Oral Implants Res. 2017;28:1-8.

35. Lee A, Fu JH, Wang HL. Soft Tissue Biotype Affects Implant Success. Implant Dent. 2011;20:e38-47.

36. Chen ST, Buser D. Esthetic outcomes following immediate and early implant placement in the anterior maxilla - a systematic review. Int J Oral Maxillofac Implant. 2014;29:186-215.

37. Kan JYK, Rungcharassaeng K, Lozada JL. Immediate Implant Placement and Provisionalization of Maxillary Anterior Single Implants. Evid Based Implant Treat Plan Clin Prot. 2016;57:174-85.

38. Nisapakultorn K, Suphanantachat S, Silkosessak O, Rattanamongkolgul S. Factors affecting soft tissue level around anterior maxillary single-tooth implants. Clin Oral Implants Res. 2010;21:662-70.

39. Zucchelli G, Mele M, Stefanini M, Mazzotti C, Marzadori M, Montebugnoli L, et al. Patient morbidity and root coverage outcome after subepithelial connective tissue and de-epithelialized grafts: A comparative randomized-controlled clinical trial. J Clin Periodontol. 2010;37:728-38. 